Research Paper:

\title{
Role of Psychological and Social Security in Predict- ing Depression Among Women Living in the Homeless Shelters of Tehran
}

\author{
Afsaneh Khadivi-Zand ${ }^{1}$ (D), Anahita Khodabakhshi-Koolae ${ }^{2^{*}}$ (D), Mohammad Reza Falsafinejad ${ }^{3}$ (D) \\ 1. Department of Counseling, Faculty of Humanities and Social Sciences, Branch of Science and Research, Islamic Azad University, Tehran, Iran. \\ 2. Department of Psychology and Education Sciences, Faculty of Humanities, Khatam University, Tehran, Iran. \\ 3. Department of Assessment and Measurement, Faculty of Psychology and Educational Sciences, Allameh Tabataba'i University, Tehran, Iran.
}

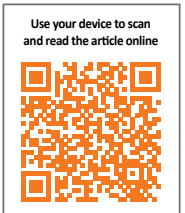

Citation: Khadivi-Zand, A., Khodabakhshi-Koolaee, A., \& Falsafinejad, M. R. 2020. Role of Psychological and Social Security in Predicting Depression Among Women Living in the Homeless Shelters of Tehran. Journal of Client-Centered Nursing Care, 6(4), pp. 213-222. https://doi.org/10.32598/JCCNC.6.4.33.13

doi https://doi.org/10.32598/JCCNC.6.4.33.13

Keywords:

Mental security, Social security, Depression, Homeless people, Women

\begin{abstract}
A B S T RA C T
Background: Homelessness is a common phenomenon in all human societies and leads to many social, psychological, and physical consequences for the homeless people and society. This study aimed to determine the role of psychological and social security in predicting depression among women living in the homeless shelters of Tehran.

Methods: It was a descriptive correlational study. The research population included all women living in the homeless shelters of Tehran, in 2020. The subjects were selected using random, multistage cluster sampling. Two homeless shelters were selected. The final sample included 150 women. The data were collected using the security-insecurity inventory and the Beck depression inventory. The collected data were analyzed using the multiple regression analysis in SPSS V. 22.

Results: The results showed that the feeling of psychological security predicts depression in women $(\mathrm{R}=0.48)$. Also, $23 \%$ of the variances in depression were explained by psychological security. Therefore, psychological security can predict depression (with $99 \%$ confidence) in these women. Moreover, the feeling of social security can predict the rate of depression in women $(\mathrm{MR}=-0.55)$. This implies that approximately $30 \%$ of the variances of depression can be explained by social security. The beta coefficient for social security was -0.55 . Accordingly, social security can predict depression (with $99 \%$ confidence) in women living in homeless shelters. The negative signs of the beta coefficients indicated a negative relationship between the predictor and the criterion variables. In other words, the higher the psychological and social security, the lower the rate of depression in women.
\end{abstract}

Conclusion: This study showed that the psychological and social security levels of these women were correlated with the degree of depression experienced. Using the insights from this study, counselors, psychiatric nurses, and other mental health professionals are suggested to create a friendly and safe environment for clients to express their feelings and lessen their depression.

\footnotetext{
"Corresponding Author:

Anahita Khodabakhshi-Koolaee, PhD.

Address: Department of Psychology and Education Sciences, Faculty of Humanities, Khatam University, Tehran, Iran.

Tel: +98 (21) 89174119

E-mail:a.khodabakhshid@khatam.ac.ir
} 


\section{Highlights}

- Homelessness is a global phenomenon that affects all human societies.

- Women become homeless due to addiction, family problems, economic poverty, and poor social conditions.

- Homeless women are suffering from sexual and physical harassment, depression, malnutrition, mental insecurity, and suicidal ideation.

- Depression is a severe mental illness among women living in homeless shelters and is rooted in their feelings of psychological and social security.

- Psychological security can predict depression in women living in homeless shelters.

- Social security can predict depression in women living in homeless shelters.

\section{Plain Language Summary}

The number of homeless women is increasing all over the world. Rapid social and technological changes; social problems, such as separation and divorce; economic poverty; unemployment; drug and alcohol addiction; the seeking of asylum due to war; and mental disorders are all reasons for women to be homeless. Thus, one of the goals of social welfare in any society is paying attention to mental health and empowering these people to have an independent life. As shown in this study, depression is prevalent in these women because of a variety of reasons, including psychological and social insecurity and the lack of a bright future.

\section{Introduction}

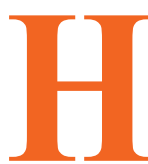

omelessness is a social phenomenon formed by various elements and factors. While leading to other social harms, homelessness can be influenced by and also influence other social harms (Ortiz-

Ospina \& Roser 2017). According to the latest reports of homelessness on September 11, 2020, more than 150 million people are estimated to be homeless worldwide. However, Habitat for Humanity International reports that by 2015 , more than 1.6 billion people lived in inadequate shelters worldwide (the homeless world cup, 2020). Among the higher reported figures, the United States reported 552.830 homeless people, and Germany, France, Canada, Australia, and Brazil all reported over 100000 homeless people in their most recent surveys (Ortiz-Ospina \& Roser 2017).

There are no exact statistics on the number of homeless people in Iran. However, in 2019, the municipality of Tehran reported more than 20.000 homeless people in this city (Borna News 2019). Moreover, demographic changes have occurred in the number of homeless people worldwide. For example, in the United States, the number of homeless women has increased in recent decades because of socioeconomic changes (Tasi et al., 2020). Besides, homeless women have special conditions due to their negative impact on the cultural and social status of society as well as their different physiological abilities, compared with men. These issues make them face more serious problems when trying to return to normal life. Furthermore, most homeless people face dietary, health, and economic limitations or addiction. Thus, they experience other social problems and harms, such as prostitution, suicide, and high-risk illnesses, such as AIDS or hepatitis, in addition to the lack of shelter and housing. Therefore, organizing this group of women and helping them socially and individually return to normal living conditions is a difficult but socially important process (Safiri \& Khadem 2014).

A review of various studies shows a high prevalence of high-risk sexual behaviors and the lack of awareness of sexually transmitted diseases among the temporary residents of homeless shelters in Tehran. It has been also shown that factors, such as illiteracy, the low awareness of high-risk behaviors, the high prevalence of these behaviors, being at reproductive age, and the lack of health-promoting behaviors threaten homeless women (Khodabakhshi-Koolaee et al., 2016A; Akhtarkhavari \& Naderloo 2019; Khodabakhshi-Koolaee et al., 2016B). 
In addition to physical difficulties, homeless women suffer from psychological problems, such as depression and suicidal ideation. For example, research has highlighted the prevalence of depression and suicide (Tasi, O’Toole \& Kearney 2017; Tasi \& Cao 2019; Payes 2020; Ayano et al., 2019), food insecurity and low mental health (Maynard et al., 2018), low life expectancy (Safiri \& Khadem 2014), low well-being (Norton et al., 2020), the risk of physical and sexual abuse and alcohol and other drug abuse (Biscotto et al., 2016; Piovani \& Aydiner-Avsar 2015) in homeless women.

Depression is a severe and recurrent disorder associated with decreased function and quality of life. The signs of depression include a depressed mood or a feeling of sadness and a lack of interest in daily affairs and enjoyment (American Psychiatric Association 2013). Also, living conditions and the feelings of psychological and social security can affect mental health and quality of life (Khodabakhshi-Koolaee et al., 2016A). Depression is a pervasive disorder that affects many people at some point in their lives. Its prevalence is higher in poor than in rich people (Khodabakhshi-Koolaee et al., 2016B) and in women than in men (Young et al., 1990).

Security is one of the basic issues in the development of human societies. The feeling of security is a kind of mentality and positive (satisfactory, convincing, and calming) psychological orientation perceived by persons in dangerous situations (Bassuk \& Beardslee 2014). Besides, psychological and social security is a necessity for all the members of society. Given that women make up almost half of the population, the study of women's issues as social and human capital is one of the most essential social needs of the country. In big cities, shelters provide a place away from problems and an opportunity for a safe life. Providing women with security is one of the most basic needs to expand their social activities and their more serious involvement in various fields. Accordingly, the current study aims to examine the role of psychological and social security in predicting depression among women living in the homeless shelters of Tehran.

\section{Materials and Methods}

\section{Study design and sample}

The present study was conducted using a descriptive correlational design. The research population included all women living in the homeless shelters of Tehran, in 2020. The participants were selected using the random and multistage cluster sampling method. To this end, two homeless shelters (one in Lavizan, District 4, and
Aftab Niloufari Shelter in Chitgar, District 22) were randomly selected from five homeless shelters for women in Tehran. The sample size was estimated as 200, using the Cochran formula. Then, referring to the centers, the researcher provided a list of the resident women. After assigning numbers to the women, the subjects were randomly selected and questionnaires were provided to them. After discarding incomplete and erroneous questionnaires, 150 women were finally selected as the study participants. Inclusion criteria were women aged 20 to 55 years, literacy to answer the questionnaires, and living in the homeless shelters for the past year.

\section{Instruments}

\section{Demographic Characteristics Questionnaire}

The questionnaire assessed the participants' demographic characteristics, including age, level of education, marital status, the number of children, occupation, and the history of addiction.

\section{Security-Insecurity Inventory (Maslow et al., 1945)}

This inventory is a 75-item tool that measures the two dimensions of psychological security and psychological insecurity. The questionnaire includes 15 subscales: social incompatibility, paranoia, self-belief, life expectancy, depression, feeling happy, social security, selfawareness, self-confidence, anger, disappointment, life expectancy, compatibility with others, feeling healthy, and feeling inferior. Each item has three alternative responses: "yes", "no", and "?". This questionnaire uses weights from +9 to -9 for the various answers of yes, no, and ?; the algebraic sums of these weights produce a score that could range from "extreme security" at the positive end of the distribution to "extreme insecurity" at the negative of the distribution.

The respondents are required to choose the alternatives that are most applicable to them. The higher the score earned on this inventory, the more are the insecurity feelings, also, a low score denotes high-security feelings among participants (Maslow et al., 1945). The lowest score on this inventory is zero showing a high level of security, and the highest score is 69 implying severe insecurity. The inventory has good reliability (0.90) (Wang et al., 2019). In this study, the reliability of the inventory was calculated as 0.86 , using the Cronbach alpha. 


\section{Beck Depression Inventory (BDI)}

This inventory was developed by Beck et al. in 1961 . It is a self-report tool that contains 21 items to assess the depression symptoms. The BDI was revised in 1996, and the revised version was used in this study (Beck et al., 1996). Each item offers four options scored on a 0 to 3 scale. Also, the maximum score gained by a respondent is 63 in BDI. Generally, a score of 14 to 19,20 to 28 , and 29 to 63 implies mild, moderate, and severe depression, respectively (Beck et al., 1996). The revised version was translated and standardized by Hamidi et al. (2015); the BDI has showed significant positive internal consistency $(\alpha=0.92)$, test-retest reliability $(r=0.64)$, and Intra-Class Correlation Coefficient ( $\mathrm{ICC}=0.81$ ). Besides, the convergent validity of BDI with general health questionnaire $(\mathrm{N}=209)$ was significantly positive $(\mathrm{r}=0.80)$ (Hamidi et al., 2015). The reliability of the inventory was reassessed in this study using the Cronbach alpha and the corresponding value was 0.83 .

\section{Social Security Scale}

This scale was developed by Sarmad, Bazargan \& Hejazi (2007). It is a 25 -item tool that assesses the level of social security, using three subscales, including social security, police performance, and government laws. The items are scored based on a five-point Likert scale ranging from 1 (totally agree) to 5 (totally disagree). However, items $10,11,12,17,18,19,20,21$, and 22 are scored reversely. The total score is calculated as the sum of the scores of all 25 items. The minimum and maximum scores on this scale are 25 and 125 , respectively. Also, a score of 25 to 50,50 to 75 , and above 75 indicates the low, moderate, and high level of social security, respectively. The reliability of the scale was 0.78 , using the Cronbach alpha coefficient Sarmad, Bazargan \& Hejazi (2007). Moreover, the reliability of the scale was recalculated in this study using the Cronbach alpha and the corresponding value was 0.81 .

\section{Procedure}

There are five homeless shelters for women in Tehran (District 5 with 20 beds, District 12 with 15 beds, District 8 with 160 beds, District 22 [Aftab Niloufari] with 150 beds, and Lavizan District with 200 beds). After obtaining permission from the university, the managers, and the officials of the Welfare and Social Partnership Services Organization in District 6 of Tehran, the researcher randomly selected the homeless shelters: Lavizan Shelter in District 4 and Aftab Niloufari Shelter in Chitgar, District 22. Next, the questionnaires were distributed among the participants and completed by them, from March 5 to June 9, 2020. The collected data were analyzed using descriptive statistics (mean, standard deviation, frequency, and percentage) and inferential statistics (correlation coefficient and multiple regression analysis) with SPSS V. 22.

\section{Results}

Table 1 shows the demographic characteristics of the study sample. Table 2 reports the mean and standard deviation for the three questionnaires used.

According to the values of the psychological security

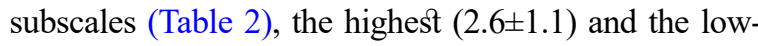
est $(1.4 \pm 0.75)$ mean scores are related to social incompatibility and self-awareness, respectively. Besides, the total score of psychological security is $28.4 \pm 7.5$. Table 3 shows the mean and standard deviation values for social security subscales and depression.

According to Table 3 , the mean and standard deviation values for social security, police performance, and governmental laws are 57.6 $\pm 15.5,10.9 \pm 3.1$, and 21.4 \pm 5.6 , respectively. Besides, the total scores of social security and depression are $90 \pm 23$ and $34.7 \pm 12.1$, respectively.

Before testing the research hypotheses, the assumptions of the univariate and multivariate regression analysis of the variables and the normal distribution of the data were checked. The results of the Kolmogorov-Smirnov test confirmed the normality assumption of the data $(\mathrm{P}>0.05)$. Regression analysis was run to test the main research hypothesis; Tables 4 and 5 show the results.

The multivariate (linear) regression coefficient for the predictor variables (ie, psychological and social security) is equal to $0.6(\mathrm{MR}=0.6$, Table 4). Therefore, the main hypothesis is confirmed $(\mathrm{P}<0.01)$. Besides, according to Table 5,37\% of the variances in depression (the criterion variable) can be explained by psychological security and social security (the predictor variables). Furthermore, the beta values show that social security $(\beta=-0.42)$ is a stronger predictor of depression, compared with psychological security $(\beta=-0.29)$. Accordingly, both psychological security and social security can predict depression (with $99 \%$ confidence) in women living in homeless shelters in Tehran. Also, the negative signs of the beta coefficients imply a negative relationship between the predictor and criterion variables. In other words, the higher the psychological and social security, the lower the level of depression in women. 
Table 1. Demographic characteristics of the study sample

\begin{tabular}{|c|c|c|}
\hline \multicolumn{2}{|c|}{ Variable } & \multirow{2}{*}{$\begin{array}{c}\text { No. (\%) } \\
49(32.60)\end{array}$} \\
\hline \multirow{4}{*}{ Age, $y$} & Under 30 & \\
\hline & $30-40$ & $51(34.0)$ \\
\hline & $41-50$ & $41(27.40)$ \\
\hline & 51 and higher & $9(6.0)$ \\
\hline \multirow{5}{*}{ Level of education } & Elementary school & $10(6.6)$ \\
\hline & High school & $64(42.6)$ \\
\hline & Diploma & $50(33.4)$ \\
\hline & Bachelor's degree & $21(14.0)$ \\
\hline & Master's degree & $5(3.4)$ \\
\hline \multirow{3}{*}{ Marital status } & Single & $72(48.0)$ \\
\hline & Divorced & $26(17.4)$ \\
\hline & Married & $52(34.6)$ \\
\hline \multirow{4}{*}{ Number of child } & Without child & 75 (50.0) \\
\hline & 1 child & $30(20.0)$ \\
\hline & 2-3 child & $35(23.4)$ \\
\hline & 4-5 child & $10(6.6)$ \\
\hline \multirow{2}{*}{ Job } & Unemployed & $97(64.6)$ \\
\hline & Employed & $53(35.4)$ \\
\hline \multirow{3}{*}{ Addiction } & Yes & $57(38.0)$ \\
\hline & No & $63(42.0)$ \\
\hline & Quit & $30(20.0)$ \\
\hline
\end{tabular}

Client- Centered Nursing Care

\section{Discussion}

The present study suggested psychological and social security as the predictors of depression in women living in homeless shelters in Tehran. This finding is consistent with the theories of the economics-based approach to psychological and social security and the previous studies in the literature. For example, Davis-Berman found that women become homeless due to broken families, also, social support and a sense of security are the key elements in their mental health (Davis-Berman 2011). Having social support and psychological security would positively affect the mental and physical health of homeless people, and paying attention to social capital is an important factor affecting the health of homeless people (Hwang et al., 2009).
The more security these women feel in their interactions with others, the more likely they will play a constructive role in society (Biscotto et al., 2016). Moreover, research shows a significant relationship between psychological security and depression. That is, the more the women feel mentally secure, the less they feel depressed. Previous studies have shown that the lack of social support from family and society, low resilience to stress, and the lack of attention to the emotional needs of people lead to the increasing isolation and loneliness of homeless people (Harp 2019; Spinola, Hoff \& Tsai 2020; Litwin, 2020).

Aghaei showed that homeless people in Tehran were increasingly exposed to low social security, migration, marginalization, and attendance in high-risk situations. In places 
Table 2. Descriptive statistics for the psychological subscales

\begin{tabular}{|c|c|}
\hline Variable & Mean \pm SD \\
\hline Social incompatibility & $2.6 \pm 1.1$ \\
\hline Paranoia & $2.13 \pm 1$ \\
\hline Self-belief & $2.5 \pm 1$ \\
\hline Life expectancy & $2.1 \pm 1.03$ \\
\hline Depression & $1.78 \pm 0.96$ \\
\hline Feeling happy & $1.9 \pm 0.98$ \\
\hline Social security & $2.2 \pm 0.9$ \\
\hline Self-awareness & $1.4 \pm 0.75$ \\
\hline Self-confidence & $1.9 \pm 1.06$ \\
\hline Anger & $1.6 \pm 1.3$ \\
\hline Disappointment & $1.7 \pm 1.2$ \\
\hline Life expectancy & $2.2 \pm 1.3$ \\
\hline Compatibility with others & $1.6 \pm 1.28$ \\
\hline Feeling healthy & $2.3 \pm 1.1$ \\
\hline Feeling inferior & $2.02 \pm 1.1$ \\
\hline Total score & $28.4 \pm 7.5$ \\
\hline
\end{tabular}

Client- Centered Nursing Care

with low social security, the variety of leisure situations increases the possibility of attending high-risk conditions and leads to addiction and cardboard sleeping (Aghaei 2019).

These findings suggest that having security is the most important need of women to expand their social activities. Homelessness has a harmful and long-lasting effect on women's mental and physical health. Thus, it is of particular importance to understand the personal factors that enable homeless women to find employment and re- enter the mainstream community. Empowering women living in shelters enables them to find the right job, especially for women who are mothers and serve as the heads of households (Brown \& Mueller 2014).

People with low and moderate social security are more likely to turn to cardboard sleeping and become homeless for various reasons, such as economic poverty, social deprivation, and the lack of social support. In other words, they receive the meanings available in the social context

Table 3. Descriptive statistics for the social security subscales and depression

\begin{tabular}{cc}
\hline Variable & Mean \pm SD \\
\hline Social security & $57.6 \pm 15.5$ \\
\hline Police performance & $10.9 \pm 3.1$ \\
\hline Governmental laws & $21.4 \pm 5.6$ \\
\hline Total score & $90.0 \pm 23$ \\
\hline Depression & $34.7 \pm 12.1$ \\
\hline
\end{tabular}


Table 4. Results of regression analysis for psychological and social security

\begin{tabular}{cccccccc}
\hline Model & SS & df & MS & F & P & MR & $\mathbf{R}^{\mathbf{2}}$ \\
\hline Regression & 8112.4 & 2 & 4056.2 & & & & 0.37 \\
Residual & 13780.8 & 147 & 93.7 & 43.2 & 0.001 & 0.6 & 0.37 \\
\hline
\end{tabular}

Table 5. Summary of regression model and regression analysis

\begin{tabular}{ccccc}
\hline Predictor Variables & B & Beta & T & P \\
\hline X1: Psychological security & -0.46 & -0.29 & -3.0 & 0.001 \\
X1: Social security & -0.22 & -0.42 & -0.56 & 0.001 \\
$\quad$ Constant & & & & \\
\hline
\end{tabular}

Client- Centered Nursing Care

and accordingly show reactions, based on the conditions of society. Addiction and cardboard sleeping are the examples of these actions (Aghaei 2019). Besides, studies conducted in Iran show that a combination of three factors has caused homelessness. The first factor is the lack of adaptation to the environment after migrating from rural to urban areas; this factor can eventually lead to the severance of family and friendly relations. Addiction is the second factor that paves the way for homelessness as a fundamental problem. Finally, the third factor accounts for physical or mental problems leading to the exclusion of the individual from the family and ultimately homelessness (Sedigh Sarvestani \& Nasr Esfahani 2011).

Generally, this study suggested that women who seek refuge in shelters in search of care and support were exposed to a variety of difficult situations. The first and most important need of such women is food, shelter, and clothing. There are various other tangible and intangible needs that must be met for these women. Besides, understanding the psychosocial needs of these women and using counseling and treatment services in centers is very important for them (Maynard et al., 2018).

Improving the attitude of people in society towards women living in shelters is one of the most serious issues that require culture-building activities at a macro scale. Many of these women have experienced indecent demands from men, such as verbal abuse and receiving protection and support in return for sexual relations. Homeless women are concerned about problems caused by homelessness and the dark future awaiting them. Family support and perceived social support play an important role in the psychological security of these women. One of the shortcomings of the present study was the lim- ited research sample that only included women living in the shelters of Tehran, in 2020. Besides, a questionnaire is a self-reporting measurement and respondents might answer them carelessly or with doubt; this may further undermine the generalizability of the present results.

\section{Conclusion}

The present study showed that psychological and social security can predict the degree of depression in women living in homeless shelters. Consequently, paying attention to the psychological and social components of the feeling of security underlies the improvement of perceived psychological and social support, and ultimately can reduce the level of depression experienced by homeless women.

\section{Ethical Considerations}

\section{Compliance with ethical guidelines}

This study was approved and registered with the Ethics Code of IR.IAU.SRB.REC.1399.064 by the Islamic Azad University, Science and Research Branch. Also, permission was obtained from the university, the managers, and the officials of the Welfare and Social Partnership Services Organization in District 6 of Tehran. Written informed consent was obtained from the participants

\section{Funding}

This article was excerpted from the MSc. thesis of the first author at the Islamic Azad University, Science and Research Branch of Tehran. 


\section{Authors' contributions}

All authors equally contributed to preparing this article.

\section{Conflict of interest}

The authors declared no conflict of interest.

\section{References}

Aghaei, S. S., 2019. [Recognition of the components of the social base and its relation with the tendency to the homelessness in Tehran (Persian)]. Social Welfare Quarterly, 19(73), pp. 97-135. [DOI:10.29252/refahj.19.73.97]

Akhtarkhavari, T., \& Naderloo, B., 2019. [The prevalence of risky sexual behaviors and awareness of STDs among temporary residents of homeless shelters in Tehran (Persian)]. Alborz University Medical Journal, 8(3), pp. 225-35. [DOI:10.29252/aums.8.3.225]

American Psychiatric Association (APA)., 2013. Diagnostic and statistical manual of mental health disorders, American Psychiatric Association, Philadelphia. [DOI:10.1176/appi.books.9780890425596]

Ayano, G., et al., 2019. Suicidal ideation and attempt among homeless people: A systematic review and meta-analysis. Psychiatric Quarterly, 90(4), pp. 829-42. [DOI:10.1007/s11126-019-09667-8] [PMID]

Bassuk, E. L., \& Beardslee, W. R., 2014. Depression in homeless mothers: Addressing an unrecognized public health issue. American Journal of Orthopsychiatry, 84(1), pp. 73-81. [DOI:10.1037/ h0098949] [PMID]

Beck, A. T., et al., 1996. Beck Depression Inventory-II [Database record], Philadelphia, APA PsycTests. [DOI:10.1037/t00742-000]

Biscotto, P. R., et al., 2016. [Compreensão da vivência de mulheres em situação de rua (Portuguese)]. Revista da Escola de Engermagem da USP, 50(5), pp. 749-55 [DOI:10.1590/s0080623420160000600006] [PMID]

Brown, C., \& Mueller, C. T., 2014. Predictors of employment among sheltered homeless women. Community, work \& family, 17(2), pp. 200-18. [DOI:10.1080/13668803.2014.890562]

Borna News, 2019. The statistics homeless in Tehran. Retrieve from: http://borna.news/ https://www.borna

Davis-Berman, J., 2011. Older women in the homeless shelter: Personal perspectives and practice ideas. Journal of Women \& Aging, 23(4), pp. 360-74. [DOI:10.1080/08952841.2011.611391] [PMID]

Taheri Tanjani, P., et al., 2015. [Validity, and reliability Beck Depression Inventory-II among the Iranian elderly population (Persian)]. Journal of Sabzevar University of Medical Sciences, 22(1), pp. 189-98. http://jsums.medsab.ac.ir/article_550_en.html

Harp, S. S., 2019. Lived experiences of homeless adults with companion animals in utilizing community services $(\mathrm{PhD}$ dissertation), Washington, Walden University.

Hamidi, R., et al, 2015. Validity and reliability Beck Depression Inventory-II among the Iranian elderly Population. Journal of
Sabzevar University of Medical Sciences, 22(1), pp. 189-98. https://www.sid.ir/en/journal/ViewPaper.aspx?ID=561046

Hwang, S. W., et al., 2009. Multidimensional social support and the health of homeless individuals. Journal of Urban Health, 86(5), pp. 791-803. [DOI:10.1007/s11524-009-9388-x] [PMID] [PMCID]

Khodabakhshi-Koolaee, A. \& Damirchi, F., 2016a. [Comparison of health-promoting lifestyle between prostitute women drug users and non-prostitute women drug users: A case-control study in Tehran (Persian)]. Nursing Journal of the Vulnerable, 3(7), pp. 59-71 http://njv.bpums.ac.ir/article-1-714-en.html

Khodabakhshi Koolaee, A., \& Damirchi, F., 2016b. Comparing quality of life among female sex workers with and without addiction. Journal of Client-Centered Nursing Care, 2(4), pp. 201-6. [DOI:10.32598/jccnc.2.4.201]

Litwin, L. H., 2020. Exploring resilience and mental health among Canadian inuit youth: Understanding wellness and piloting a prevention program. Retrieve from: https://yorkspace-new.library.yorku.ca/xmlui/handle/10315/37384

Maynard, M., et al., 2018. Food insecurity and mental health among females in high-income countries. International Journal of Environmental Research and Public Health, 15(7), p. 1424. [DOI:10.3390/ ijerph15071424] [PMID] [PMCID]

Maslow, A. H., et al., 1945. A clinically derived test for measuring psychological security-insecurity. The Journal of Ggeneral Psychology, 33(1), pp. 21-41. [DOI:10.1080/00221309.1945.10544493]

Norton, C. L., et al., 2020. Utilizing outdoor adventure therapy to increase hope and well-being among women at a homeless shelter. Journal of Outdoor Recreation, Education, and Leadership, 12(1). [DOI:10.18666/JOREL-2020-V12-I1-9928]

Ortiz-Ospina, E., \& Roser, M., 2017. Homelessness. Our world in data. Retrieve from: https://ourworldindata.org/homelessness

Payes, A., 2020. The relationship of legal history to mental health symptoms and suicidality among homeless men in a residential recovery program $(\mathrm{PhD}$. dissertation), Kalifornien, Pepperdine University.

Piovani, C., \& Aydiner-Avsar, N., 2015. The gender impact of social protection policies: A critical review of the evidence. Review of Political Economy, 27(3), pp. 410-41. [DOI:10.1080/09538259.20 15.1063311]

Safiri, K. H., \& Khadem, R., 2014, [An evaluation of life expectancy status among homeless women in Tehran City (Case of study): A temporary holding center for homeless women of Tehran municipality, "Samansraye Lavizan") (Persian)]. Journal of Iranian Social Development Studies (JISDS), 6(1), pp. 51-70. https://jisds. srbiau.ac.ir/article_3157_57c283a854dea4ee78fec625aa87c47a. pdf?lang=en

Sarmad, Z., Bazargan, A., \& Hejazi, E., 2007. [Research methods in behavioral sciences (Persian)],Tehran, Agahe Pub. https://www. adinehbook.com/gp/product/9643290514

Sedigh Sarvestani, R., \& Nasr Esfahani, A., 2011. [Drug abuse, social exclusion, and homelessness in Tehran: A qualitative study (Persian)], Iranian Journal of Social Problems, 1(4), pp. 1-18. https:/ / ijsp.ut.ac.ir/article_22692_0433be6da18584bc62b21015f3a3e619. pdf?lang=en

Spinola, S., Hoff, R. A., \& Tsai, J., 2020. A psychosocial mediational model of homelessness among US male and female veterans who 
served in Iraq and Afghanistan. Health \& Social Care in the Community, 29(2), pp. 453-63. [DOI:10.1111/hsc.13106] [PMID]

Tsai, J., et al., 2020. Changing demography of homeless adult populations. Perspectives in Public Health, p. 1757913920919796. [DOI:10.1177/1757913920919796] [PMID]

Tsai, J., O'Toole, T., \& Kearney, L. K., 2017. Homelessness as a public mental health and social problem: New knowledge and solutions. Psychological Services, 14(2), pp. 113-17. [DOI:10.1037/ser0000164] [PMID]

Tsai, J., \& Cao, X. (2019). Association between suicide attempts and homelessness in a population-based sample of US veterans and non-veterans. Journal of Epidemiology and Community Health, 73(4), pp. 346-52. [DOI:10.1136/jech-2018-211065] [PMID]

Young, M. A., et al., 1990. Sex differences in the lifetime prevalence of depression: does varying the diagnostic criteria reduce the female/male ratio? Journal of Affective Disorders, 18(3), pp. 187-92. [DOI:10.1016/0165-0327(90)90035-7]

Wang, J., Long, R., \& Chen, H., 2019. Measuring the psychological security of urban residents: Construction and validation of a new scale. Frontiers in Psychology, 10, p. 2423. [DOI:10.3389/ fpsyg.2019.02423] [PMID] [PMCID] 
This Page Intentionally Left Blank 